\title{
The effect of protein deficiency upon peritoneal healing and peritoneal wound contraction in the rat
}

\author{
By T. J. MOTT, E. C. ASHBY, B. P. FLANNERY AND H. ELLIS \\ Surgical Unit, Westminster Hospital, London, $S W_{\mathrm{I}}$
}

(Received 27 August 1968-Accepted ro February 1969)

\begin{abstract}
I. Adult rats were maintained on a protein-deficient diet for 6 weeks following which laparotomy was performed and peritoneal wounds of standard size were constructed.

2. The diet resulted in a progressive weight loss and a fall in plasma protein. Tissue protein, expressed as percentage protein in dried voluntary muscle, did not fall significantly.

3. Following laparotomy the rats were killed in groups on successive days and the peritoneal wounds were removed for measurement of area and for histological examination.

4. There was no apparent difference between control and protein-deficient animals in the rate or extent of peritoneal wound contraction although there was histological evidence of delay of collagen formation in the protein-deficient animals. This supports the theory that collagen formation is not a function of wound contraction.
\end{abstract}

There have been a number of laboratory studies of the effect of various pathological states upon the healing of the peritoneum. In the past we have observed the influence of steroids, diabetes and immaturity in the rat and ascorbic acid deficiency in the guinea-pig (Ellis, Harrison \& Hugh, 1965), irradiation in the rat (Venables, Ellis \& Burns, I967) cytotoxic drugs in the rat (Gordon, Smith \& Ellis, I967) and uraemia in the rabbit (Mott \& Ellis, 1967).

The present study concerns the effect of protein deficiency in the rat, and in addition to macroscopical and histological observations an attempt has been made to compare quantitatively the decrease in size of the peritoneal wound as healing progresses.

\section{MATERIAL AND METHODS}

\section{General outline}

Male Wistar rats were used weighing from $270 \mathrm{~g}$ to $4 \mathrm{I} 8 \mathrm{~g}$. They were divided into a control series and a 'protein-deficient' series, and were housed in standard metal cages in groups of six. The control animals were fed on Oxoid $4 \mathrm{I} \mathrm{B} \mathrm{diet,} \mathrm{and} \mathrm{the}$ protein-deficient rats were maintained on a diet obtained from Professor Yudkin (Table I). Both groups received water ad lib.

In a preliminary survey it was found that mature rats given the protein-deficient diet would survive, on average, for ro weeks. Therefore, 6 weeks was taken as an arbitrary time to establish 'protein deficiency' within the terms of the experiment. When this time had elapsed the healing experiments were performed and the diet was continued until the rats were killed.

The healing experiments consisted of fashioning wounds in the parietal peritoneum of the abdominal wall and are described in detail below. At varying time intervals afterwards the animals were killed. On this occasion blood was obtained by ventricular 
puncture for haemoglobin and plasma protein determination; at the same time portions of abdominal wall were removed for measurement and histological examination of the peritoneal wound, also portions of thigh muscle were excised for determination of nitrogen content.

Table 1. Protein-free diet $(g)$

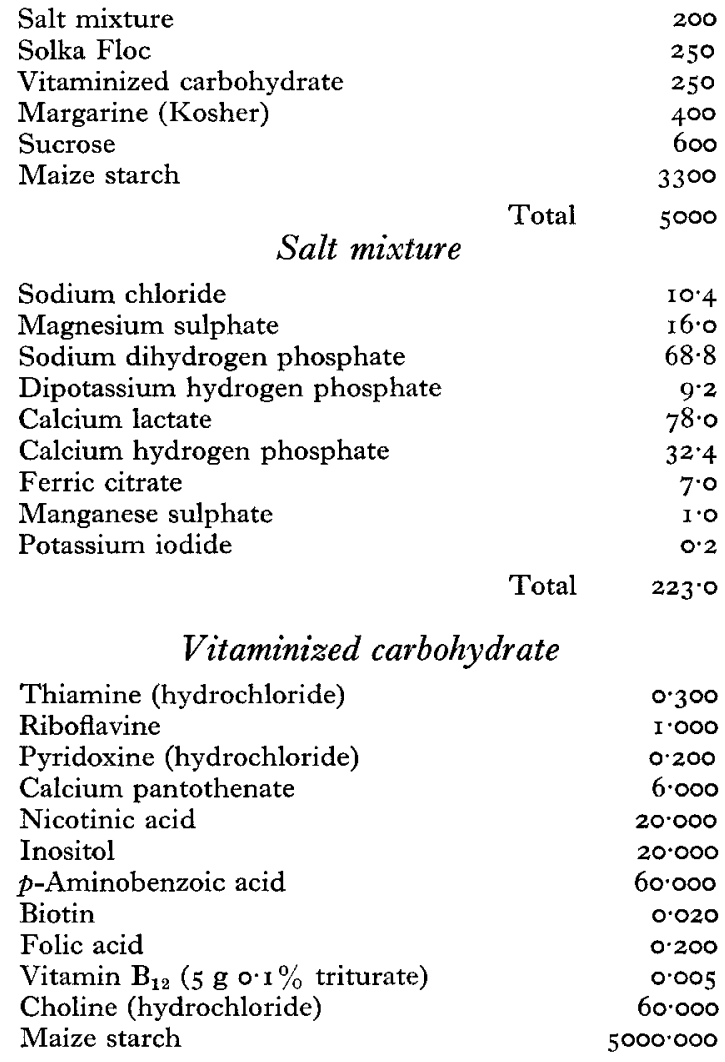

\section{Plasma and tissue protein}

Blood was obtained when the animals were killed and the total plasma protein was estimated by the Biuret method using an autoanalyser (Technicon).

The total nitrogen content of striated muscle in both protein-deficient and control rats was determined. About $\mathrm{I} g$ of thigh muscle was dried at $\mathrm{I} I \mathrm{O}^{\circ}$ for $4 \mathrm{~h}$. Total nitrogen was then determined by the Kjeldahl method, the results being expressed as percentage protein in dried muscle. This was calculated assuming an average of $16 \%$ nitrogen in protein.

\section{Peritoneal healing}

For this, the major part of the experiment, sixty control animals were used and forty-eight 'protein-deficient'. Of these, one control succumbed during the anaesthetic, and sixteen 'protein-deficient' rats died at operation or shortly afterwards; all the rats that suffered operative or postoperative death were discarded. 
Each rat was anaesthetized with Nembutal and ether, the abdominal fur was clipped and the animal was placed supine upon the operating table. The skin of the abdominal wall was cleansed with benzalkonium solution. Strict asepsis was not observed, but no case became overtly infected.

A $5 \mathrm{~cm}$ midline incision was made through all layers of the abdominal wall. On each side in turn the edge of the abdominal wall was grasped with several fine artery forceps and folded back over a $2 \mathrm{~cm}$ wide metal support to expose upward the parietal peritoneum. By means of a metal template, a square was traced on the peritoneum with a scalpel and when the template was removed the area of peritoneum so delineated was peeled from the underlying muscle with fine forceps. On the right-hand side a $\mathrm{I} \mathrm{cm}$ square of peritoneum was excised at a distance of $I \cdot 5 \mathrm{~cm}$ from the midline and on the left-hand side a $2 \mathrm{~cm}$ square of peritoneum was taken at a distance of $0.5 \mathrm{~cm}$ from the midline. The abdominal wound was then closed with two layers of continuous thread sutures and the animal returned to its cage. To ensure uniformity all these procedures and the subsequent pinning out of the specimens were performed by one person.

The animals were killed at intervals of $24 \mathrm{~h}, 2,3,4,5,6,7$, Io and I4 days.

The skin from the abdominal wall was removed and the midline incision reopened. The peritoneal defects were identified on each side and excised within a $3 \mathrm{~cm}$ square of abdominal muscle. The specimens were pinned flat on cork and fixed in $10 \%$ formol saline.

After fixation for $24 \mathrm{~h}$ the specimen was removed from the fixative and the outline of the peritoneal wound was traced on to portions of transparent plastic sheet with a stylus. The outlines thus obtained were mounted on I $\mathrm{mm}$ squared graph paper for measurement of area. The specimens were then bisected through the peritoneal defect and the tissue processed and embedded in paraffin. Sections were cut and adjacent sections were stained with haemotoxylin and eosin, Van Geison and the reticulin stain of Gomori.

\section{RESULTS}

\section{General effect of the protein-deficient diet}

Animals on the protein-deficient diet had a uniform rate of weight loss and after 6 weeks body-weight was, on the average, $65 \%$ of the original weight. At this time several of the rats appeared weak and listless, and one-third of the 'protein-deficient' rats died at operation or shortly afterwards. There was no significant fall in haemoglobin level.

\section{Plasma and tissue protein}

The mean total plasma protein of the control rats was $6.8 \mathrm{~g} / \mathrm{lo0} \mathrm{g} \pm 0.4$. The mean value for the 'protein-deficient' animals was significantly lower at a level of $4 \cdot 4 \mathrm{~g} / \mathrm{ro0} \mathrm{g}$ $\pm 0.6(P<0.001)$.

In contrast, when fourteen pairs of control and protein-deficient animals were examined there was no significant difference in the protein content of voluntary muscle in either group. The mean percentage of protein in dried muscle of the controls was $88 \cdot 2 \pm 12 \cdot 0$ and of the protein-deficient animals it was $91 \cdot 8 \pm 7 \cdot 3(0.4>P>0.3)$. 


\section{Macroscopical appearances of the peritoneal defects}

In the control series the macroscopical appearances of the wounds of successive animals were as described previously (Ellis $e t a l$. 1965). During the first 2 days the peritoneal defects were a vivid red colour with an irregular surface. On the $3^{\text {rd }}$ day the surface appeared smoother and the colour less pronounced. On the $4^{\text {th }}$ day the surface was covered by a smooth white patch which by the 14 th day had become more translucent and smaller in size.

The protein-deficient animals showed identical changes for the first 3 days. On the $4^{\text {th }}$ day a distinct white colour did not develop, but instead a thinner white translucent appearance which persisted until the $14^{\text {th }}$ day. These wounds also decreased in size.

\section{Histological appearances}

The histological appearances of the control and protein-deficient animals were similar during the first 2 days. In both groups the wound was covered by a cellular

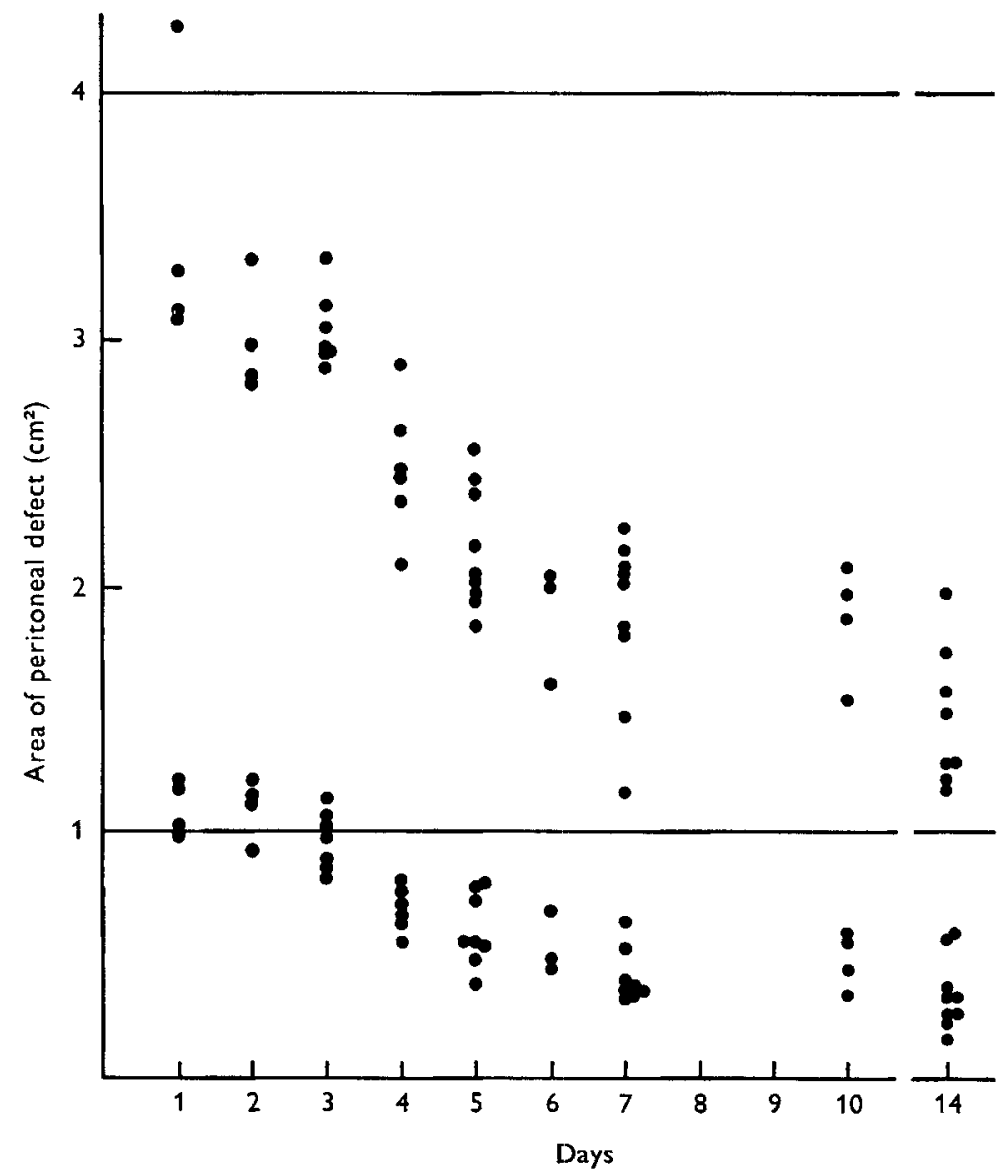

Fig. I. Scattergram to show the areas of the peritoneal wounds of each control rat plotted against time. The upper series represents the $2 \mathrm{~cm}$ wounds and the lower series represents the I $\mathrm{cm}$ wounds. 
exudate containing histiocytes and monocytes with a few polymorphonuclears and occasional mast cells. If anything, the exudate of the protein-deficient animals was a little less cellular.

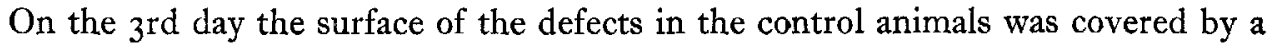
continuous layer of cells and beneath this the exudate was occupied by proliferating fibroblasts. On the $4^{\text {th }}$ day young collagen fibres began to appear between the fibro-

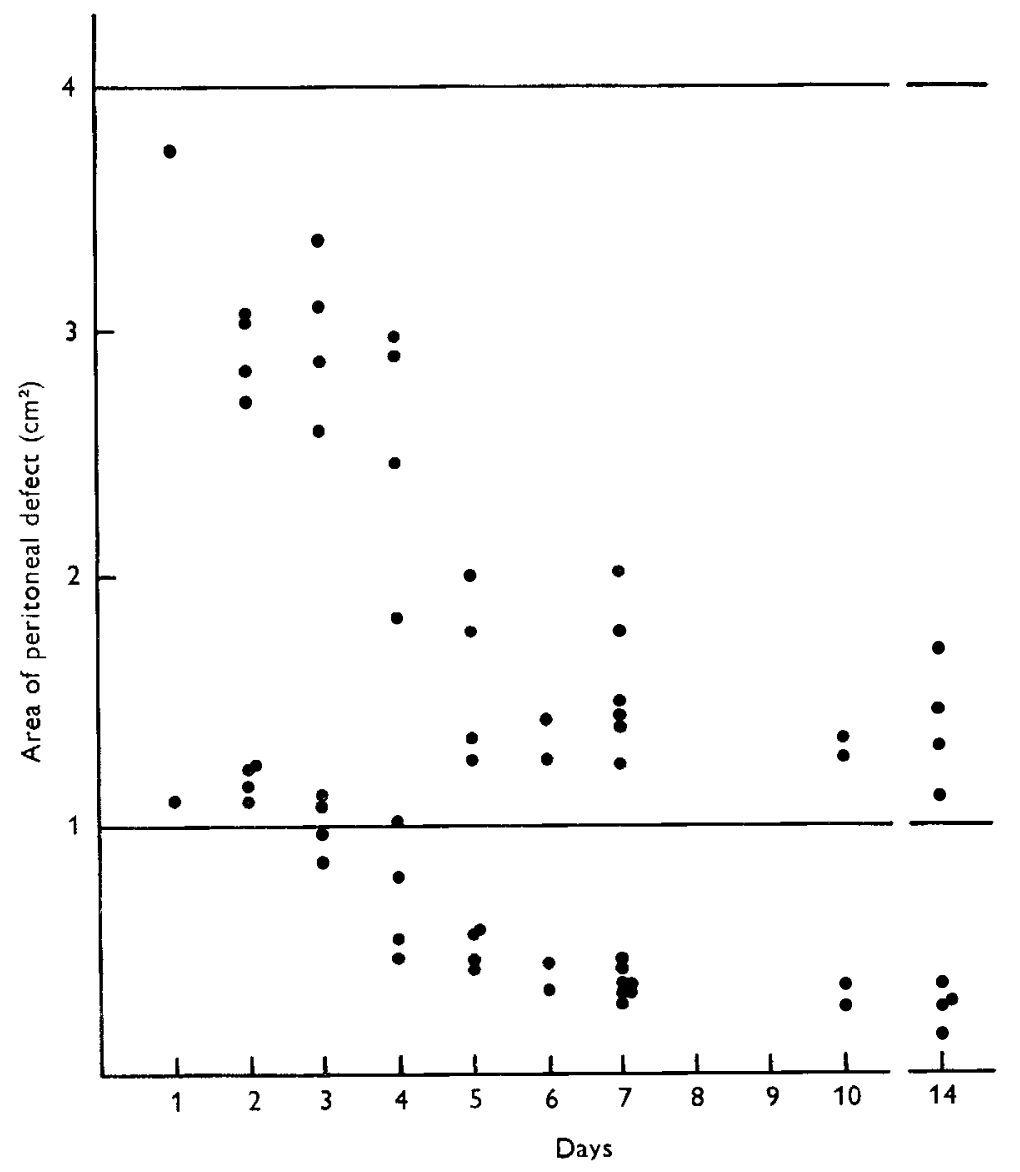

Fig. 2. Scattergram to show the areas of the peritoneal wounds of each protein-deficient rat plotted against time. The upper series represents the $2 \mathrm{~cm}$ wounds and the lower series represents the $\mathrm{I} \mathrm{cm}$ wounds.

blasts and these were established by the $5^{\text {th }}$ day, by which time the surface layer of cells was flattened and indistinguishable from the mesothelium of the surrounding peritoneum. By the 7 th day the collagen fibres were more numerous and dense and were orientated parallel to the surface of the wound. By the $14^{\text {th }}$ day the layer of collagen was thinner and more dense and the cellular content was less.

The sequence of events in the protein-deficient animals followed that of the controls except that the formation of an intact mesothelium was delayed until the 5 th day and the formation of established young collagen was delayed until the 6th day. In amount 
and density of collagen fibres, a 7 th-day protein-deficient animal resembled a 5 th-day control. On the I $^{\text {th }}$ day the layer of collagen was thinner, less dense, and the fibres less orientated in contrast to the controls.

Micrographs taken on the $3^{\mathrm{rd}}$, $5^{\text {th }}$ and $7^{\text {th }}$ days demonstrate the histological differences (Pl. I).

\section{Measurement of peritoneal wound contraction}

The areas of the peritoneal wounds of the control and protein-deficient animals were plotted against time (Figs. I and 2). It will be seen that there are more figures for control than for protein-deficient animals. There was a quite wide scatter in the values

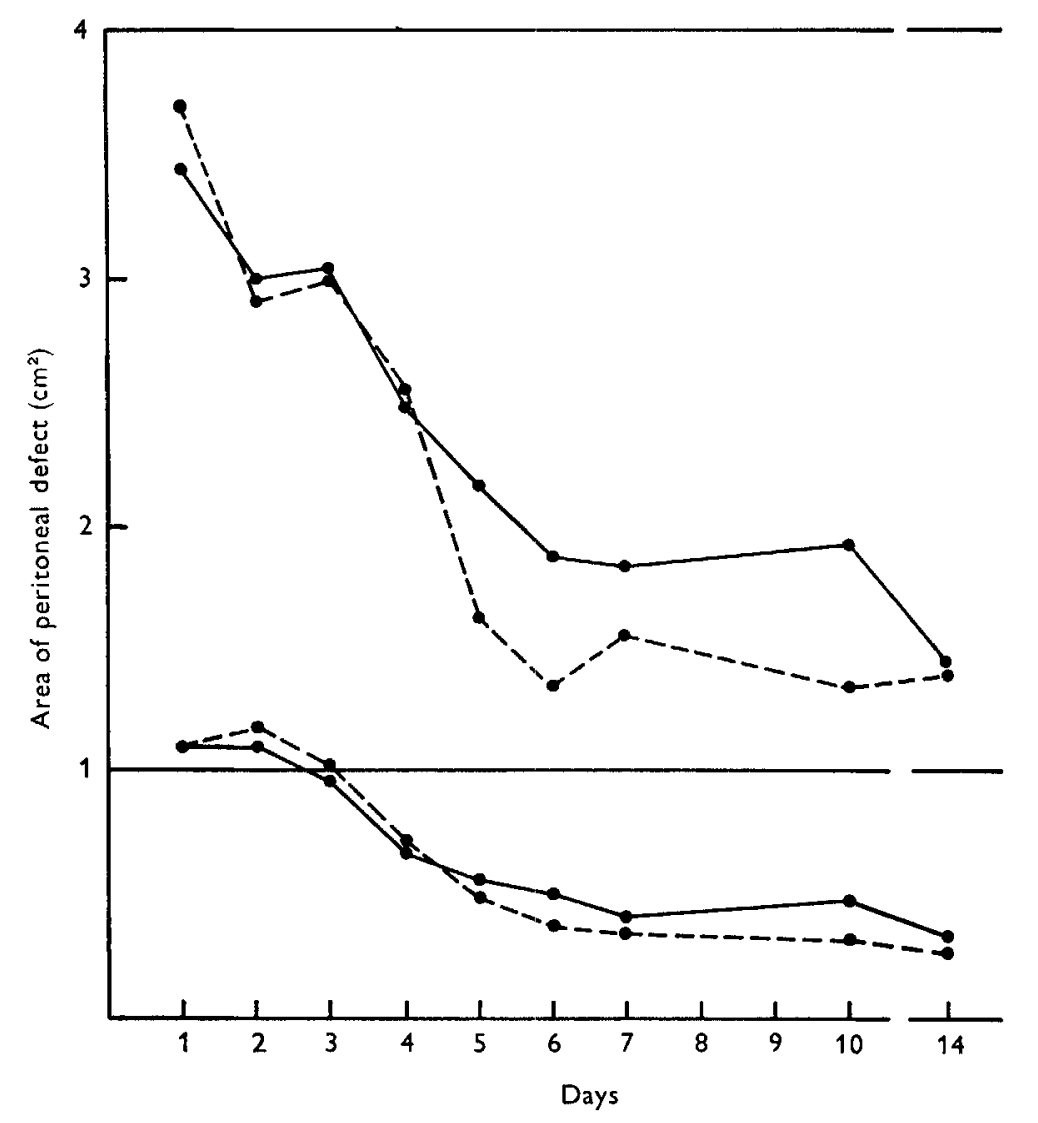

Fig. 3. Graph to show the similarity of the contraction curves of the peritoneal wounds of control and protein-deficient rats when the means of the values shown in Figs. $I$ and 2 are plotted together. The upper curves represent the $2 \mathrm{~cm}$ wounds and the lower curves represent the $1 \mathrm{~cm}$ wounds.

for the $2 \mathrm{~cm}$ defects, but the $\mathrm{I} \mathrm{cm}$ values were more consistent; this is presumably because the former defects were nearer the midline with subsequent distortion during pinning out and fixation.

The average areas for both control and 'protein-deficient' rats were calculated and both plotted on the same graph for comparison (Fig. 3). In the wounds $\mathrm{I} \mathrm{cm}^{2}$ the 
maximum amount of wound contraction occurred between the $3^{\text {rd }}$ and $5^{\text {th }}$ days, with the curve flattening out at the 6th day.

It is also evident that there was no significant difference between the $\mathrm{I}$ cm contraction curves for either group of animals.

\section{DISCUSSION}

It has long been realized that protein deficiency in man is associated with poor wound healing. Localio, Chassin \& Hinton (1948) studied three groups of patients; a normally nourished group, a second group obviously suffering from malnutrition and a third group who had experienced postoperative wound disruption. In each patient the protein content of serum, rectus sheath, peritoneum and muscle was estimated. The tissue samples were removed at operation, subjected to alkaline hydrolysis, and the total protein was calculated per $\mathrm{g}$ wet tissue. The results indicated that serum proteins may be quite normal in the presence of quite marked depletion of tissue protein and hence may be a poor guide to the general protein nutrition of the patient. It is interesting to compare this with our results in the 'protein-deficient' rat of a significantly lower serum protein, but no difference in tissue protein (although the latter was expressed as a percentage of dry weight).

The retarding influence of protein deficiency upon healing has been demonstrated several times in the laboratory and it is caused by lack of methionine (Localio, Morgan \& Hinton, I948; Williamson, McCarthy \& Fromm, I95 ; Udupa, Woessner \& Dunphy, 1956). These authors found that histologically the protein-deficient animals were shown to produce highly cellular granulation tissue deficient in collagen fibres with little orientation of the fibroblasts across the wound. These results agree with our own observations of the impaired collagen formation in the depths of the healing peritoneal wound of the protein-deficient rat.

The reason for the delay in the formation of a surface 'mesothelial' layer in the protein-deficient animal is more obscure. It has been shown that after wounding the peritoneum the formation of a new mesothelium is produced by metaplasia of intraperitoneal macrophages (Eskeland, 1966), and it can only be presumed that deficiency of protein depresses this rate of cell division.

In this experiment a quantitative measurement of peritoneal wound contraction was made. Many such experiments have been performed previously on skin wounds which have the advantage of allowing daily observation and measurement on the same wound. However, there are the disadvantages that open wounds are obscured by adherent scabs, where removal is likely to damage the wound bed and distort the wound, and when dressings are used their removal causes comparable damage. Thus the peritoneal wound in some respects is an ideal model on which to study contraction.

It has been shown that the phase of wound contraction in the skin of the rat is greatest between the $5^{\text {th }}$ and the $9^{\text {th }}$ days (Abercrombie, Flint \& James, 1954). Our results indicate that for the peritoneum contraction occurs at an earlier stage, that is, between the 3 rd and 6 th days. This is probably because the peritoneal cavity provides 
an isothermic environment in which cell movement has been shown to be more rapid (Reddan \& Rothstein, 1965).

Peritoneal wound contraction is not decreased or delayed by protein deficiency with the accompanying decrease of collagen. Evidence that collagen is not implicated in contraction comes from scorbutic guinea-pigs, since in ascorbic acid deficiency (Wolbach \& Howe, 1926) little collagen is laid down. Abercrombie, Flint \& James (1956) found that wounds in such animals contracted not significantly less than those in non-scorbutic controls. Our results appear to confirm these findings in the 'protein-deficient' state.

We would like to express our thanks to Professor J. Yudkin for the proteindeficient diet, and to Mr D. Geddes for the measurements of tissue protein.

\section{REFERENCES}

Abercrombie, M., Flint, M. H. \& James, D. W. (1954). F. Embryol. exp. Morph. 2, 264. Abercrombie, M., Flint, M. H. \& James, D. W. (1956). F. Embryol. exp. Morph. 4, 167. Ellis, H., Harrison, W. \& Hugh, T. B. (1965). Br. F. Surg. 52, 471.

Eskeland, G. (1966). Regeneration of Peritoneum. Oslo: Universitetsforlaget.

Gordon, J. A., Smith, G. M. R. \& Ellis, H. (1967). Br. F. Cancer 21, 763 .

Localio, S. A., Chassin, M. D. \& Hinton, J. W. (1948). Surgery Gynec. Obstet. 86, 107. Localio, S. A., Morgan, M. D. \& Hinton, J. W. (1948). Surgery Gynec. Obstet. 86, 582. Mott, T. J. \& Ellis, H. (1967). Br. F. Urol. 39, 34r.

Reddan, J. R. \& Rothstein, H. (1965). Exp. Cell Res. 40, 442.

Udupa, J. N., Woessner, J. F. \& Dunphy, J. E. (1956). Surgery Gynec. Obstet. 102, 639.

Venables, C., Ellis, H. \& Burns, J. E. (1967). Br. F. Radiol. 40, 275.

Williamson, M. B., McCarthy, T. H. \& Fromm, H. J. (195I). Proc. Soc. exp. Biol. Med. 77, 303.

Wolbach, S. B. \& Howe, P. R. (1926). Archs Path. (Lab. Med.) I, I.

\section{EXPLANATION OF PLATE}

Photomicrographs of vertical sections of the healing peritoneum of rats at various stages. The upper layer is the fibrous exudate undergoing organization and showing fibroplasia with the formation of collagen. The sections were stained with Van Geison stain and the photographs were taken using a green filter so that collagen, where present, shows up as dark intracellular strands. The lower layer is the underlying muscle of the abdominal wall.

(a) Control at 3 days. A new layer of flattened cells has formed on the surface. There is a brisk cellular reaction.

(b) Protein-deficient at 3 days. A layer of flattened cells has not formed. The cellular reaction is less.

(c) Control at 5 days. There is much fibroplasia within the exudate and collagen is present between the cells.

(d) Protein-deficient at 5 days. Intracellular collagen has not appeared.

(e) Control at 7 days. The cellular component of the exudate has diminished and there is much collagen arranged in strands parallel to the surface.

( $f$ ) Protein-deficient at 7 days. The cellular component has not diminished and such collagen as is present is 'fluffy' and not orientated parallel to the surface. 

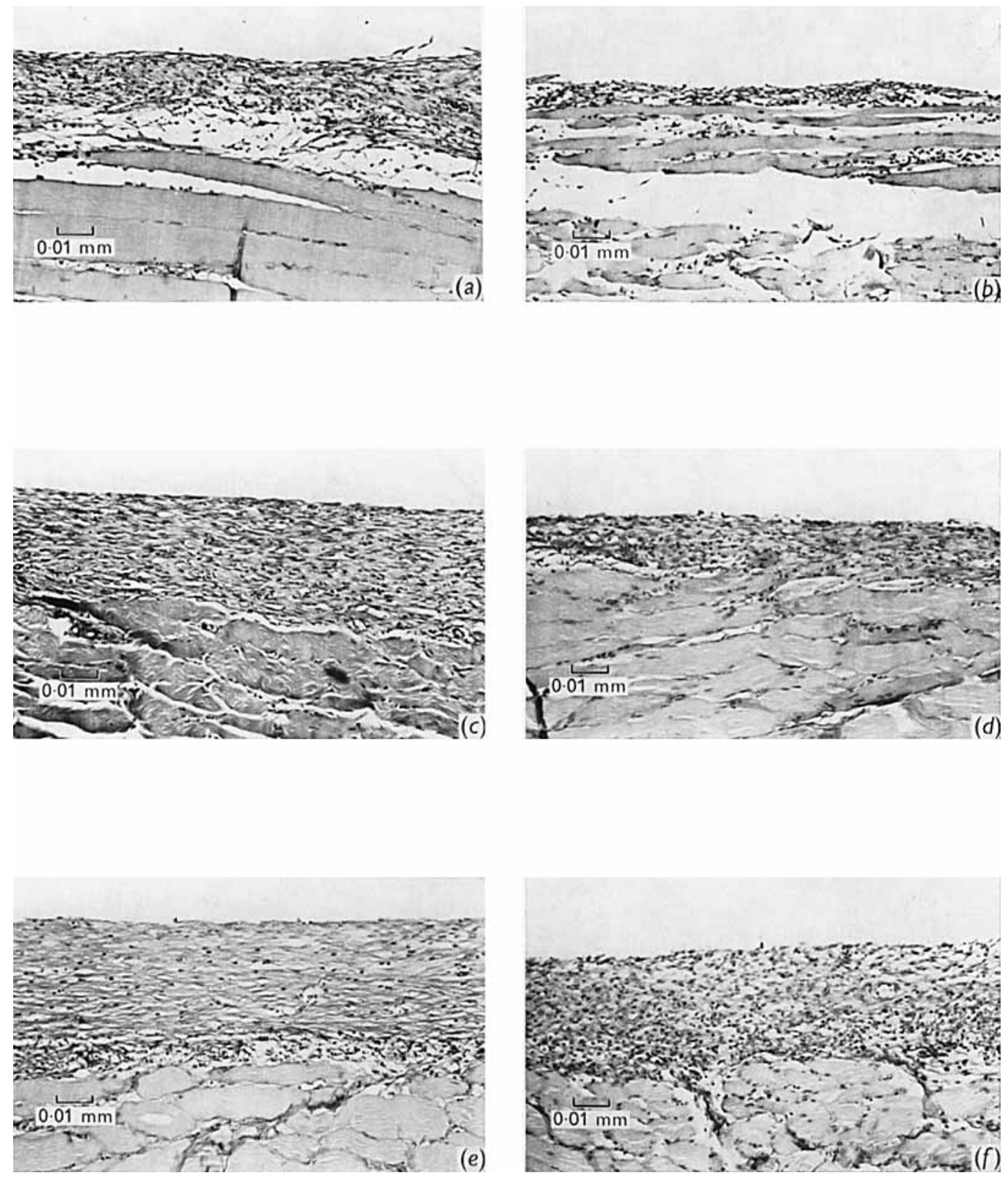